\title{
Short-term exposure to air pollution in a road tunnel enhances the asthmatic response to allergen
}

\author{
M. Svartengren ${ }^{* * * *}$, V. Strand ${ }^{* * *}$, G. Bylin***, L. Järup ${ }^{* *,+, \#}$, G. Pershagen ${ }^{* *,+}$
}

Short-term exposure to air pollution in a road tunnel enhances the asthmatic response to allergen. M. Svartengren, V. Strand, G. Bylin, L. Järup, G. Pershagen. (C)ERS Journals Ltd 2000 .

ABSTRACT: The aim of this study was to assess whether air pollution in road tunnels would promote asthmatic reactions in persons with mild allergic asthma.

Twenty volunteers with mild allergic asthma were exposed, inside a car, for $\mathbf{3 0}$ min in a Stockholm city road tunnel. As a control, the subjects were exposed to much lower pollution levels in a suburban area. Four hours after the exposure, the subjects inhaled a low dose of allergen. Asthmatic reaction during the early phase was measured as the increase in specific airway resistance $15 \mathrm{~min}$ after allergen inhalation and during the late phase as the decrease in lung function forced expiratory volume in one second 3-10 h after allergen inhalation. Asthma symptoms and drug use were monitored up to $18 \mathrm{~h}$ after allergen inhalation.

The median nitrogen dioxide level during exposure was $313 \mu \mathrm{g} \cdot \mathrm{m}^{-3}$ (range 203462). The median levels of particles with $50 \%$ cut-off aerodynamic diameters of 10 (PM10) and $2.5 \mu \mathrm{m}$ (PM2.5) were 170 (range 103-613) and 95 (range 61-218) $\mu \mathrm{g} \cdot \mathrm{m}^{-3}$, respectively. Subjective symptoms during tunnel exposure were not pronounced. However, subjects exposed to tunnel $\mathrm{NO}_{2}$ levels of $\geq 300 \mu \mathrm{g} \cdot \mathrm{m}^{-3}$ had a significantly greater early reaction, following allergen exposure, as well as lower lung function and more asthma symptoms during the late phase, compared to control. Also, subjects with PM2.5 exposure $\geq 100 \mu \mathrm{g} \cdot \mathrm{m}^{-3}$ had a slightly increased early reaction compared to control.

In conclusion, exposure to air pollution in road tunnels may significantly enhance asthmatic reactions to subsequently inhaled allergens.

Eur Respir J 2000; 15: 716-724.
*Division of Occupational Medicine, Dept of Public Health Sciences, Karolinska Institute, Stockholm, **Dept of Environmental Health, Stockholm County Council, Stockholm, ${ }^{* * *}$ Dept of Respiratory and Allergic Diseases, Huddinge University Hospital, Huddinge and Dept of Medicine, Karolinska Institute, Stockholm, and Institute of Environmental Medicine, Karolinska Institute, Stockholm, Sweden. "Dept of Epidemiology and Public Health, Imperial College School of Medicine, London, UK.

Correspondence: M. Svartengren, Division of Occupational Medicine, Dept of Public Health Sciences, Karolinska Institute at Karolinska Hospital, S-171 76 Stockholm, Sweden. Fax: 46851773766.

Keywords: Allergen challenge, allergic asthma, nitrogen dioxide, particles, road tunnel

Received: August 271998

Accepted after revision January 232000

This study was supported by grants from the Swedish National Road Administration (Head Office and Region Stockholm), the City of Stockholm and Stockholm County Council.
Motor vehicles are the dominant source of air pollution in many cities, including Stockholm. The adverse health effects of short-term exposure to car exhaust are often inferred from studies of separate components such as nitrogen oxides and particulates. Nitrogen dioxide $\left(\mathrm{NO}_{2}\right)$ increases bronchial responsiveness to both nonspecific agents [1] and allergens [2-4] in asthmatic subjects. Experimental studies suggest that asthmatics are also more sensitive to particles than healthy subjects [5]. Increased numbers of hospital visits due to asthma or other respiratory illnesses have been associated with daily variations in the concentrations of particles with a $50 \%$ cut-off aerodynamic diameter of $10 \mathrm{~mm}$ (PM10) [6-9] and $\mathrm{NO}_{2}[10,11]$.

The health effects of short-term exposure to motor vehicle exhaust have mainly been assessed by means of controlled chamber studies [12]. These studies involve controlled exposure to a single pollutant, or sometimes a combination of two or more pollutants. Controlled studies have also been performed using "diluted diesel exhaust" $[13,14]$. However, real life exposure is to a mixture and more complex. Furthermore, temperature and humidity during real exposure often differ from that in the laboratory environment.
The aim of this study was to assess whether air pollution in road tunnels would promote asthmatic reactions in persons with mild allergic asthma. Respiratory symptoms and pulmonary function were investigated in such subjects during and after a brief stay in a tunnel during the early morning rush hour. Furthermore, an assessment was made of the influence of the tunnel exposure on the subject's sensitivity to subsequent allergen inhalation, several hours later.

\section{Study design}

\section{Methods}

Twenty subjects with allergic asthma were studied on two separate occasions, at least 4 weeks apart, between December 1996 and February 1997, i.e. outside the pollen season. The weather in Stockholm during the study period was fairly cold with a mean temperature of $-1.4^{\circ} \mathrm{C}$ (range $12.4-8.6$ ) and relative humidity of $76 \%$ (range $32-95$ ). The subjects were randomly allocated to start with tunnel or control exposure. For the tunnel exposure the test subjects sat for 30 min during the morning rush hour (08:00-09:00 h) in a car parked at the roadside in the Söderleden road tunnel. This tunnel has a length of $\sim 1,500 \mathrm{~m}$ and is used by 
$\sim 35,000$ vehicles $\cdot$ day $^{-1}$. Ventilation of the tunnel is brought about by the movement of the vehicles themselves, and can be assisted by fans and ventilation towers. The windows of the car were closed and the ventilation fan inside the car was on during exposure. The ventilation system was not equipped with a pollen filter. For the control, subjects stayed at a hotel near Huddinge University Hospital, in southern Stockholm, in an area with low levels of air pollution. Exposure measurements were taken just outside the hotel. Respiratory symptoms and pulmonary function were measured immediately before, during and after the 30-min tunnel exposure and likewise during the control experiment. Four hours after the exposure, i.e. at $\sim 13: 00 \mathrm{~h}$, the test subjects were challenged with a low dose (see below) of inhaled allergen. Asthmatic reactions during the early and late phase were monitored by means of hourly pulmonary function measurements and symptom registration until bedtime, i.e. $23: 00 \mathrm{~h}$, which corresponds to a 10-h follow-up of the asthmatic reaction to allergen.

\section{Subjects}

Subjects were recruited from the Huddinge hospital outpatient clinic for respiratory and allergic diseases and by advertising in newspapers. All subjects gave informed consent to participation in the study. The study was approved by the Ethical Committee at Huddinge University Hospital.

Twenty subjects, 10 females and 10 males, aged 19-55 yrs, with mild seasonal asthma and allergy to pollen (13 birch, seven timothy grass) participated. Lung function (forced expiratory volume in one second (FEV1)) at inclusion was $99 \pm 12 \%$ of the predicted (mean $\pm \mathrm{SD}$ ). Anthropometric and clinical data are given in table 1 . The subjects were included if they had a diagnosis of asthma based on reversible attacks of dyspnoea during the pollen season and bronchial hyperresponsiveness to histamine. Allergy to either birch or timothy grass pollen was confirmed via a positive skin-prick test with a weal diameter of $>3 \mathrm{~mm}$ [15], and a positive bronchial challenge with the relevant allergen. Six subjects showed a late asthmatic reaction with a maximal decrease in FEV1 of $>15 \%, 3-10 \mathrm{~h}$ after allergen challenge. The study subjects used inhaled $\beta_{2}$-agonists as needed and 11 used inhaled steroids during the pollen season (May-August). However, none of them received inhaled or oral steroids during the study period. All subjects were nonsmokers (14 neversmokers and six exsmokers for $\geq 2$ yrs). All subjects were also sensitized to animals (dog 19, cat 15, and horse nine) and three to dust mites according to a skin-prick test. No subject had pets in their homes. Seven subjects had domestic gas appliances, which may be an important source of $\mathrm{NO}_{2}$ exposure.

\section{Exposure measurements}

In the tunnel, $\mathrm{NO}_{2}$ /oxides of nitrogen $\left(\mathrm{NO}_{\mathrm{X}}\right)$ sampling was carried out inside and outside the car, which was parked in the tunnel during the whole of the exposure period. Air samples from the two measuring points were alternately sucked into a chemiluminescence instrument (AC $31 \mathrm{M}$ chemiluminescent nitrogen oxides analyser;
Environment SA, Poissy, France) for $30 \mathrm{~s}$ with $60 \mathrm{~s}$ washout in between. Sampling of the PM10 and particles with a $50 \%$ cut-off aerodynamic diameter of $2.5 \mu \mathrm{m}$ (PM2.5) fractions was performed inside the car only, simultaneously using two instruments (TEOM 1400; Rupprecht\& Patashnick, Albany, NY, USA). The $\mathrm{NO}_{2} / \mathrm{NO}_{\mathrm{X}}$ and particulate fraction data were recorded and stored in a computer as 15 -min means. At the control site, $\mathrm{NO}_{2} / \mathrm{NO}_{\mathrm{X}}$ sampling was carried out outdoors at a height of $3 \mathrm{~m}$ and PM10 and PM2.5 sampling at a height of $2 \mathrm{~m}$ using the same methodology as in the tunnel.

Individual exposures to $\mathrm{NO}_{2}$ during the exposure and control day were also measured with personal passive (filter badge) samplers (Toyo Roshi Kaisha, Tokyo, Japan). The analysis technique as well as the accuracy and reproducibility of measurements using the sampler have been presented in detail elsewhere [16]. The measuring time started just before the subjects entered the tunnel and lasted $24 \mathrm{~h}$.

\section{Symptom registration}

The study subjects were asked to indicate their general respiratory status on a visual analogue scale, $0-10$, before they entered the car within the tunnel and at the end of exposure. During the stay in the tunnel, they also answered 15 questions covering different symptoms of the respiratory tract as well as general symptoms. For the control exposure, similar registrations were performed in the morning, when the subjects arrived at the hospital. These questions have been used previously in chamber exposure studies [3]. A scale with discrete values from 1-7 was used, 1 indicating no symptoms and 7 indicating very strong symptoms.

After the allergen challenge, the subjects kept a diary of respiratory symptoms and medication. Separate scales were used for night- and daytime symptoms of asthma and symptoms of the nose and eyes. Two combination variables were created. One variable was computed as the sum of asthma symptoms during the evening, night and morning after the exposure. The other combination variable was calculated as the total number of $\beta_{2}$-inhalations during the day, night and morning after the exposure.

\section{Whole body plethysmography}

Specific airway resistance (sRaw) and thoracic gas volume (TGV) were measured in a constant-volume body plethysmograph (Model 2000 TB; Cardio-Pulmonary Instruments, Houston, TX, USA), according to DuBoIs and colleagues $[17,18]$. The gas flow/box pressure slopes were measured at a gas flow of $0.5--0.5 \mathrm{~L} \cdot \mathrm{s}^{-1}$ (expiration/ inspiration) as the mean of two or three slopes. The mouth pressure/box pressure slopes were measured between the end points, again as the mean of two or three curves. All panting manoeuvres were performed at $\sim 1 \mathrm{~Hz}$, the subject being guided by a metronome.

\section{Histamine bronchial challenge}

Histamine provocation tests at inclusion were performed using an automatic inhalation-synchronized dosimeter jet nebulizer (Spire Elektro 2; Respiratory Care Center, 
Table 1. - Anthropometric and clinical data

\begin{tabular}{|c|c|c|c|c|c|c|c|c|c|c|}
\hline $\begin{array}{l}\text { Subject } \\
\text { No }\end{array}$ & Sex & $\begin{array}{l}\text { Age } \\
\text { yrs }\end{array}$ & $\begin{array}{c}\text { Asthma } \\
\text { duration } \\
\text { yrs }\end{array}$ & $\begin{array}{l}\text { Smoking } \\
\text { status }\end{array}$ & $\begin{array}{l}\text { FEV1 } \\
\% \text { pred }\end{array}$ & $\begin{array}{l}\text { Domestic } \\
\text { gas } \\
\text { appliances }\end{array}$ & $\begin{array}{l}\text { Histamine dose } \\
\text { at inclusion mg }\end{array}$ & $\begin{array}{l}\text { Inhaled } \\
\text { allergen }\end{array}$ & $\begin{array}{l}\text { Allergen dose } \\
\text { inhaled }^{\dagger} \\
\text { SQ units }\end{array}$ & $\begin{array}{l}\text { LPR Maximal fall } \\
\text { in } \mathrm{FEV}^{\#} \%\end{array}$ \\
\hline 1 & $\mathrm{M}$ & 38 & 8 & Ex & 115 & - & 223 & B & 55 & 3 \\
\hline 2 & $\mathrm{~F}$ & 30 & 17 & Ex & 110 & - & 178 & B & 35 & 11 \\
\hline 3 & $\mathrm{~F}$ & 26 & 25 & Never & 94 & - & 326 & $\mathrm{~T}$ & 28 & 11 \\
\hline 4 & M & 45 & 40 & Never & 88 & + & 64 & B & 28 & 22 \\
\hline 5 & M & 32 & 6 & Never & 73 & - & 58 & B & 21 & 27 \\
\hline 6 & $\mathrm{~F}$ & 23 & 18 & Never & 107 & - & 23 & $\mathrm{~T}$ & 14 & -5 \\
\hline 7 & $\mathrm{~F}$ & 36 & 11 & Never & 93 & - & 76 & B & 28 & 13 \\
\hline 8 & M & 26 & 20 & Never & 108 & + & 58 & $\mathrm{~T}$ & 55 & 58 \\
\hline 9 & M & 23 & 19 & Ex & 106 & - & 34 & B & 21 & 26 \\
\hline 10 & M & 30 & 20 & Never & 108 & + & 461 & B & $35^{\S}$ & -2 \\
\hline 11 & M & 24 & 20 & Ex & 114 & + & 461 & B & 330 & 21 \\
\hline 12 & M & 19 & 8 & Never & 105 & - & 97 & $\mathrm{~T}$ & 165 & 0 \\
\hline 13 & $\mathrm{~F}$ & 27 & 6 & Never & 108 & - & 737 & B & 330 & 14 \\
\hline 14 & M & 33 & 32 & Never & 95 & + & 20 & B & 28 & 12 \\
\hline 15 & $\mathrm{~F}$ & 33 & 13 & Never & 73 & - & 137 & B & $21 / 14^{\S}$ & 3 \\
\hline 16 & $\mathrm{~F}$ & 41 & 13 & Never & 107 & + & 478 & $\mathrm{~T}$ & 35 & 5 \\
\hline 17 & M & 55 & 2 & Never & 99 & - & 699 & B & 165 & 22 \\
\hline 18 & $\mathrm{~F}$ & 54 & 50 & Never & 89 & - & 39 & B & 28 & 9 \\
\hline 19 & $\mathrm{~F}$ & 24 & 6 & Never & 88 & - & 175 & $\mathrm{~T}$ & 660 & 4 \\
\hline 20 & $\mathrm{~F}$ & 27 & 8 & Never & 108 & + & 699 & $\mathrm{~T}$ & 83 & 5 \\
\hline All & & $32 \pm 10$ & $17 \pm 12$ & & $99 \pm 12$ & & $156(58-461)$ & & $35(28-103)$ & $11(3-22)$ \\
\hline
\end{tabular}

Data for all subjects are presented as mean \pm SD or median (interquartile range). *: causing $100 \%$ increase in specific airway resistance at inclusion; ${ }^{\dagger}: 4 \mathrm{~h}$ after tunnel/control exposure; ${ }^{\#}: 3-10 \mathrm{~h}$ after allergen challenge at inclusion (late phase reaction); ${ }^{\S}:$ reduced allergen dose, see Asthmatic reaction during the early phase. FEV1: forced expiratory volume in one second; SQ: standardized quality; M: male; F: female; B: birch pollen; T: timothy grass pollen. +: present; -: absent.

Hämeenlinna, Finland) with an adjustable aerosol delivery time according to a previously described method [3, 19]. Doubling doses of histamine diphosphate at three concentrations, 1,8 and $64 \mathrm{mg} \cdot \mathrm{mL}^{-1}$ were administered from an initial dose of $14 \mu \mathrm{g}$ until a $100 \%$ increase in sRaw was reached. sRaw and TGV were measured 3 min after each dose. The provocation dose causing a doubling of the $\mathrm{s} R \mathrm{aw}$ was calculated by linear interpolation on a logarithmic scale.

\section{Allergen challenge and allergen inhalation}

Four hours after tunnel or control exposure, an allergen challenge was carried out. The subject rested for $15 \mathrm{~min}$ in the laboratory, and then $\mathrm{s} R$ aw and TGV were measured using the whole body plethysmograph described above.

The allergen challenge at the inclusion test and the allergen inhalation during the study were provided via the dosimeter jet nebulizer described above. Standardized freeze-dried birch or timothy grass pollen allergen extracts (Aquagen, Copenhagen, Denmark) were used at a maximum of four concentrations, 1,000, 4,000, 16,000 and 64,000 standardized quality (SQ) allergen units $\cdot \mathrm{mL}^{-1}$. For each concentration, two and four breaths could be taken, and, if needed, this was followed by eight and 16 breaths at the highest concentration. sRaw and TGV were measured $15 \mathrm{~min}$ after each dose. After measurement of baseline sRaw, the subject inhaled doubling doses of allergen, starting from an initial dose of 14 SQ units until a $100 \%$ increase in $\mathrm{s}$ Raw was reached. The dose causing a doubling of the sRaw for the allergen was calculated by linear interpolation on a logarithmic scale. The inhaled allergen dose during the study was set to $40 \%$ of this dose or the dose step above (table 1). The median allergen dose used was 34 SQ units (range 7-590). For safety reasons, the inhalation started with $20 \%$ of the inclusion dose. Another $20 \%$ was then inhaled provided that the sRaw increase, after $15 \mathrm{~min}$, was $<50 \%$ compared to baseline. If the sRaw increase after the first dose was $50-75 \%$ compared to baseline, the second allergen dose was reduced to $10 \%$ of the inclusion dose. Fifteen minutes after the second dose, sRaw and TGV were measured again. These measurements are referred to as the early phase asthmatic reaction.

\section{Spirometry}

At inclusion, pulmonary function was followed hourly in all subjects. The best value of FEV1 was called "ever best", and FEV1 obtained thereafter were expressed as a percentage of this "ever best" FEV1. On tunnel and control exposures days, subjects were asked to measure peak expiratory flow (PEF) and forced vital capacity every hour from 08:00 h, using a portable computerized spirometer (Diary Card spirometer (B); Micromedical, Chatham, UK). After the allergen inhalation, the subjects went home and continued to measure FEV1 hourly for $\geq 10 \mathrm{~h}$. The subjects were instructed to inhale bronchodilators if needed or if the FEV1 decreased by $\geq 30 \%$. The maximal percentage fall in FEV1 $3-10 \mathrm{~h}$ after allergen challenge is referred to as the late phase asthmatic reaction.

\section{Statistical methods}

The statistical package SPSS (SPSS Inc., Chicago, IL, USA) for Windows (6.1.3) was used for all statistical analyses. The differences in pulmonary function, subjective symptoms and concentrations between tunnel exposure and control were analysed using the Wilcoxon's 
signed-rank test. Differences in responses between subjects exposed to high and low levels of pollution were compared using the Wilcoxon rank sum test. A priori dichotomizations of $300 \mu \mathrm{g} \cdot \mathrm{m}^{-3} \mathrm{NO}_{2}$ and $100 \mu \mathrm{g} \cdot \mathrm{m}^{-3} \mathrm{PM} 2.5$ were chosen based on expected pollution levels within the tunnel. Rank correlation analysis was used to estimate Spearman correlation coefficients. A p-value of $<0.05$ using twotailed tests was considered statistically significant.

\section{Results}

\section{Air pollution exposure}

Concentrations of $\mathrm{NO}_{2}$ in the tunnel outside and inside the car were similar. The median $\mathrm{NO}_{2}$ concentration during rush hour 08:00-09:00 h, Monday to Friday) was 289 $\mu \mathrm{g} \cdot \mathrm{m}^{-3}$ (range 179-688) inside the car and $11 \mu \mathrm{g} \cdot \mathrm{m}^{-3}$ (range 0-51) at the hotel. PM10 and PM2.5 levels inside the car during rush hour were $126 \mu \mathrm{g} \cdot \mathrm{m}^{-3}$ (range 75-907) and $93 \mu \mathrm{g} \cdot \mathrm{m}^{-3}$ (range 60-262) respectively, and the levels near the hotel were $7 \mu \mathrm{g} \cdot \mathrm{m}^{-3}$ (range $2-17$ ) and $5 \mu \mathrm{g} \cdot \mathrm{m}^{-3}$ (range 2-11).

Individual exposures in the car are given in table 2 . The median $\mathrm{NO}_{2}$ concentration was $313 \mu \mathrm{g} \cdot \mathrm{m}^{-3}$ (range 203462). The $\mathrm{NO}_{2}$ concentration in the car was highly correlated with the concentrations of $\mathrm{NO}_{\mathrm{X}}$ in the car $(\mathrm{r}=0.91), \mathrm{NO}_{2}$ in the tunnel $(\mathrm{r}=0.83)$, and $\mathrm{NO}_{\mathrm{X}}$ in the tunnel $(\mathrm{r}=0.77)$. Furthermore, there was a significant association between $\mathrm{NO}_{2}$ concentration measurements in the car and the difference in the badge measurements between tunnel exposure and the control day $(r=0.47$, $\mathrm{p}=0.036$ ).

The 24-h median exposure to $\mathrm{NO}_{2}$ measured with the personal passive sampler (badge) was $29 \mu \mathrm{g} \cdot \mathrm{m}^{-3}$ (range 2050) during tunnel exposure and $22 \mu \mathrm{g} \cdot \mathrm{m}^{-3}$ (range 10-38) during control exposure. The difference was statistically significant $(\mathrm{p}<0.001)$. Domestic gas appliances contributed a median of $8 \mu \mathrm{g} \cdot \mathrm{m}^{-3}$ to the $24-\mathrm{h}$ median concentrations $(\mathrm{p}=0.011)$.

The PM10 and PM2.5 concentrations in the car were 170 $\mu \mathrm{g} \cdot \mathrm{m}^{-3}$ (range 103-613) and $95 \mu \mathrm{g} \cdot \mathrm{m}^{-3}(61-218)$, respectively. PM10 and PM2.5 concentrations were highly correlated $(r=0.91)$. However, there were only very weak associations between $\mathrm{NO}_{2}$ levels and PM10 or PM2.5 concentrations $(\mathrm{r}<0.18)$.

\section{Effects during air pollution exposure}

Questionnaire data showed that, in the tunnel, several symptom scores were increased. The greatest differences were found for noise, smell and cough irritation (median difference 3.5, 3.0 and 1.0). The values for self-perceived general respiratory status were significantly higher (worse) in the tunnel (median 2.05, range $0-8.2$ on the visual analogue scale) than before tunnel exposure (median 1.0, range $0-5.0, \mathrm{p}<0.004$ ) or at the control site (median 0.6, range $0-7.2, \mathrm{p}<0.006)$. Higher $\mathrm{NO}_{2}$ levels were significantly associated with nasal congestion $(\mathrm{rS}=-0.44, \mathrm{p}=$ 0.050 ). After dichotomization at a $\mathrm{NO}_{2}$ exposure of 300 $\mu \mathrm{g} \cdot \mathrm{m}^{-3}$, no significant differences were found.
FEV1 in the car was determined in the sitting position, which might slightly decrease the values compared to other measurements, which were all performed with the subjects in a standing position. The FEV1 in the car (mean 3.47, median 3.33, range 1.46-5.26 L) was not different from the morning value (mean 3.48, median 3.38, range 1.51-5.13 $\mathrm{L}, \mathrm{p}=0.84$ ), but lower compared to later on in the morning (mean 3.56, median 3.38, range 1.63-5.51 L, p=0.002) and just before allergen challenge (mean 3.56, median 3.36, range $1.69-5.38 \mathrm{~L}, \mathrm{p}=0.001)$. There was an association between $\mathrm{NO}_{2}$ and FEV1 change in the car $(\mathrm{rS}=0.48, \mathrm{p}=$ 0.042 ) but no association between PM2.5 concentration and pulmonary function at any time before allergen challenge.

\section{Asthmatic reaction during the early phase}

All subjects completed the allergen inhalation test. However, in subject No. 10, the allergen dose was reduced from 40 to $20 \%$ of the inclusion dose at both exposures. Furthermore, in subject No. 15, the total allergen dose at control exposure was reduced to $30 \%$ because of symptoms of asthma, and the patient was excluded from comparisons of the effects of allergen inhalation.

Lung function results are given in table 3 . There were no differences in $\mathrm{sRaw}$ or TGV, before allergen inhalation, between tunnel and control exposure. Median sRaw increased $44 \%$ (from 5.0 to $7.2 \mathrm{cmH}_{2} \mathrm{O} \cdot \mathrm{s}$ ) after allergen inhalation following the tunnel exposure, and $31 \%$ (from 5.1 to $6.7 \mathrm{cmH}_{2} \mathrm{O} \cdot \mathrm{s}$ ) for control exposure. Median TGV increased from 3.5 to $3.7 \mathrm{~L}(\mathrm{p}<0.001)$ after tunnel plus allergen exposure compared to 3.4 to $3.2 \mathrm{~L}(\mathrm{p}=0.94)$ after control plus allergen exposure. The increases in both $\mathrm{s} R \mathrm{aw}$

Table 2. - Individual exposure to $\mathrm{NO}_{2}$ or particles

\begin{tabular}{|c|c|c|c|c|}
\hline \multirow[b]{2}{*}{$\begin{array}{l}\text { Subject } \\
\text { No }\end{array}$} & \multicolumn{2}{|c|}{$24 \mathrm{~h}$ badge } & \multicolumn{2}{|c|}{ 30-min exposure in car } \\
\hline & $\begin{array}{c}\text { Tunnel } \\
\mathrm{NO}_{2} \mu \mathrm{g} \cdot \mathrm{m}^{-3}\end{array}$ & $\begin{array}{c}\text { Hotel } \\
\mathrm{NO}_{2} \mu \mathrm{g} \cdot \mathrm{m}^{-3}\end{array}$ & $\begin{array}{c}\mathrm{NO}_{2} \\
\mu \mathrm{g} \cdot \mathrm{m}^{-3}\end{array}$ & $\begin{array}{l}\mathrm{PM} 2.5 \\
\mu \mathrm{g} \cdot \mathrm{m}^{-3}\end{array}$ \\
\hline 1 & 29 & 12 & 462 & 87 \\
\hline 2 & 35 & 16 & 462 & 87 \\
\hline 3 & 26 & 21 & 203 & 68 \\
\hline 4 & 38 & 25 & 279 & 78 \\
\hline 5 & 25 & 27 & 203 & 68 \\
\hline 6 & 27 & 22 & 324 & 128 \\
\hline 7 & 29 & 30 & 324 & 128 \\
\hline 8 & 50 & 30 & 355 & 101 \\
\hline 9 & 31 & 24 & 410 & 91 \\
\hline 10 & 31 & 21 & 275 & 108 \\
\hline 11 & 47 & 18 & 355 & 101 \\
\hline 12 & 20 & 10 & 237 & 77 \\
\hline 13 & 22 & 21 & 271 & 76 \\
\hline 14 & 37 & 38 & 303 & 77 \\
\hline 15 & 29 & 10 & 298 & 61 \\
\hline 16 & 21 & 18 & 275 & 108 \\
\hline 17 & 22 & 24 & 313 & 139 \\
\hline 18 & 25 & 12 & 313 & 139 \\
\hline 19 & 26 & 22 & 329 & 218 \\
\hline 20 & 33 & 26 & 321 & 144 \\
\hline Median & 29 & 22 & 313 & 95 \\
\hline Minimum & 20 & 10 & 203 & 61 \\
\hline Maximum & 50 & 38 & 462 & 218 \\
\hline
\end{tabular}

PM2.5: particles with 50\% cut-off aerodynamic diameter of 2.5 $\mu \mathrm{m}$. 
and TGV after tunnel plus allergen exposure were significantly greater than after control plus allergen exposure ( $p=0.025$ and $p=0.01$, respectively). A similar tendency with a greater effect for tunnel plus allergen exposure (median 4.5, range -2.2-19.1\%) than for control plus allergen (median 1.6, range $-4.7-17.7 \%$ ) was also found for fall in FEV1 $(\mathrm{p}=0.11)$.

In order to assess the influence by level of exposure in the tunnel of the two measured air pollutants, the group was divided into two parts. A priori dichotomizations were chosen based on expected pollution levels within the tunnel. Twelve of the subjects had tunnel $\mathrm{NO}_{2}$ exposure levels of $\geq 300 \mu \mathrm{g} \cdot \mathrm{m}^{-3}$. These subjects exhibited a significantly greater early phase reaction after allergen challenge following tunnel exposure (median sRaw increased $44 \%$ from 5.3 to $7.7 \mathrm{cmH}_{2} \mathrm{O} \cdot \mathrm{s}$ ) than following control exposure (median sRaw increased 24\% from 5.1 to $6.4 \mathrm{cmH}_{2} \mathrm{O} \cdot \mathrm{s}$ ). The seven individuals with $\mathrm{NO}_{2}$ exposure levels below $300 \mu \mathrm{g} \cdot \mathrm{m}^{-3}$ did not differ from control $(\mathrm{p}=0.61)$. In the group as a whole, there was no overall association between $\mathrm{NO}_{2}$ exposure and difference in $\mathrm{s} R$ aw change caused by allergen challenge between tunnel and control $(\mathrm{rS}=0.36$, $\mathrm{p}=0.14$ ) (fig. 1a).

Ten of the subjects had PM2.5 exposure levels of $\geq 100$ $\mu \mathrm{g} \cdot \mathrm{m}^{-3}$. These subjects had a marginally greater early reaction after allergen challenge following tunnel exposure (median sRaw increased 36\% from 4.9 to $6.6 \mathrm{cmH}_{2} \mathrm{O} \cdot \mathrm{s}$ ) than after control exposure (median sRaw increased $22 \%$ from 5.1 to $\left.6.3 \mathrm{cmH}_{2} \mathrm{O} \cdot \mathrm{s}\right)(\mathrm{p}=0.038)$. There was no difference between PM2.5 exposure below and above 100 $\mu \mathrm{g} \cdot \mathrm{m}^{-3}$. There was no overall association between PM2.5 exposure and the early reaction $(\mathrm{r}=0.14, \mathrm{p}=0.53)$ (fig. $1 \mathrm{~b})$.

\section{Asthmatic reaction during the late phase}

The test subjects had significantly more asthma symptoms during the evening after the tunnel exposure than after the control exposure $(\mathrm{p}=0.016)$. Furthermore, the combined asthma symptoms during the evening, night and morning after the exposure tended to be worse $(\mathrm{p}=0.085)$. These symptoms were significantly correlated with $\mathrm{NO}_{2}$ exposure (fig. $2 \mathrm{a}),(\mathrm{rS}=0.72, \mathrm{p}=0.001)$ but not PM2.5 exposure (fig. 2b) $(\mathrm{rS}=0.32, \mathrm{p}=0.18)$.

The combined asthma symptoms variable was significantly increased compared to control $(p=0.028)$, when $\mathrm{NO}_{2}$ exposure was $>300 \mu \mathrm{g} \cdot \mathrm{m}^{-3}$. The group with $\mathrm{NO}_{2}$ exposure above $300 \mu \mathrm{g} \cdot \mathrm{m}^{-3}$ had significantly more asthma symptoms during the exposure evening compared to control $(\mathrm{p}=0.026)$ and more symptoms during the night after allergen inhalation compared to the group with exposure $<300 \mu \mathrm{g} \cdot \mathrm{m}^{-3}(\mathrm{p}=0.024)$. Corresponding analyses for PM2.5 with a dichotomization at $100 \mu \mathrm{g} \cdot \mathrm{m}^{-3}$ showed a slight but nonsignificant effect for the combined asthma symptom variable.

The mean number of $\beta_{2}$-agonist inhalations during the $20 \mathrm{~h}$ following tunnel exposure was low, 0.8 , compared to 0.7 for the control exposure. The combined medication variable based on the number of $\beta_{2}$-agonist inhalations indicating positive association with $\mathrm{NO}_{2}$ exposure $(\mathrm{rS}=$ $0.56, \mathrm{p}=0.014)$. The group with $\mathrm{NO}_{2}$ exposure $>300 \mu \mathrm{g} \cdot \mathrm{m}^{-3}$

Table 3. - Asthmatic reaction during the early phase

\begin{tabular}{|c|c|c|c|c|c|c|c|c|}
\hline \multirow[b]{3}{*}{$\begin{array}{l}\text { Subjects } \\
\text { No }\end{array}$} & \multicolumn{4}{|c|}{ Tunnel exposure } & \multicolumn{4}{|c|}{ Control exposure } \\
\hline & \multicolumn{2}{|c|}{$\mathrm{s} R$ aw $\mathrm{cmH}_{2} \mathrm{O} \cdot \mathrm{s}$} & \multicolumn{2}{|c|}{ TGV L } & \multicolumn{2}{|c|}{$\mathrm{s} R$ aw $\mathrm{cmH}_{2} \mathrm{O} \cdot \mathrm{s}$} & \multicolumn{2}{|c|}{ TGV L } \\
\hline & $\begin{array}{l}\text { Before } \\
\text { allergen }\end{array}$ & $\begin{array}{c}\text { After } \\
\text { allergen }\end{array}$ & $\begin{array}{l}\text { Before } \\
\text { allergen }\end{array}$ & $\begin{array}{c}\text { After } \\
\text { allergen }\end{array}$ & $\begin{array}{l}\text { Before } \\
\text { allergen }\end{array}$ & $\begin{array}{l}\text { After } \\
\text { allergen }\end{array}$ & $\begin{array}{l}\text { Before } \\
\text { allergen }\end{array}$ & $\begin{array}{c}\text { After } \\
\text { allergen }\end{array}$ \\
\hline 1 & 5.0 & 8.3 & 3.6 & 4.2 & 4.0 & 6.2 & 4.1 & 3.9 \\
\hline 2 & 4.7 & 7.0 & 3.0 & 3.6 & 5.0 & 5.9 & 3.2 & 3.2 \\
\hline 3 & 5.1 & 6.9 & 2.9 & 3.0 & 5.0 & 7.7 & 3.2 & 3.2 \\
\hline 4 & 8.3 & 13.2 & 4.3 & 5.4 & 9.7 & 10.0 & 4.3 & 4.5 \\
\hline 5 & 6.2 & 10.4 & 2.6 & 2.9 & 6.0 & 8.5 & 2.7 & 2.6 \\
\hline 6 & 4.8 & 7.2 & 2.6 & 2.8 & 5.2 & 5.2 & 2.7 & 2.5 \\
\hline 7 & 6.7 & 12.9 & 2.7 & 2.9 & 5.9 & 8.7 & 2.4 & 2.2 \\
\hline 8 & 5.9 & 16.7 & 4.8 & 6.1 & 6.1 & 12.5 & 4.9 & 5.7 \\
\hline 9 & 6.8 & 8.1 & 3.5 & 3.7 & 5.9 & 6.7 & 4.2 & 3.5 \\
\hline $10^{+}$ & 4.9 & 6.1 & 4.5 & 4.8 & 5.1 & 6.1 & 4.7 & 4.5 \\
\hline 11 & 4.4 & 5.4 & 4.1 & 4.2 & 4.1 & 5.2 & 4.4 & 5.0 \\
\hline 12 & 6.3 & 8.1 & 4.3 & 4.4 & 4.2 & 8.3 & 4.1 & 4.5 \\
\hline 13 & 4.6 & 6.0 & 2.0 & 2.1 & 4.8 & 5.0 & 2.3 & 2.2 \\
\hline 14 & 4.9 & 7.0 & 4.2 & 4.5 & 5.6 & 8.7 & 3.8 & 4.0 \\
\hline $15^{\#}$ & 7.3 & 10.0 & 2.3 & 2.5 & 9.9 & 15.5 & 2.8 & 3.2 \\
\hline 16 & 4.9 & 5.8 & 3.7 & 3.7 & 5.6 & 7.4 & 3.8 & 4.1 \\
\hline 17 & 4.4 & 5.1 & 3.0 & 3.0 & 4.1 & 4.8 & 3.1 & 3.1 \\
\hline 18 & 6.1 & 10.7 & 2.0 & 2.3 & 6.7 & 8.9 & 2.2 & 2.3 \\
\hline 19 & 5.8 & 8.3 & 2.8 & 3.3 & 4.3 & 6.4 & 3.2 & 3.0 \\
\hline 20 & 4.7 & 5.6 & 4.1 & 3.9 & 4.0 & 4.7 & 3.4 & 3.2 \\
\hline Median & 5.0 & 7.2 & 3.5 & 3.7 & 5.1 & 6.7 & 3.4 & 3.2 \\
\hline Minimum & 4.4 & 5.1 & 2.0 & 2.1 & 4.0 & 4.7 & 2.2 & 2.2 \\
\hline Maximum & 8.3 & 16.7 & 4.8 & 6.1 & 9.7 & 12.5 & 4.9 & 5.7 \\
\hline
\end{tabular}

*: 15 min after allergen challenge; ${ }^{+}$: provocation dose of $20 \%$ of inclusion dose used for both exposures; ${ }^{*}$ : subject excluded because different provocation doses were used for the tunnel ( $40 \%$ of inclusion dose) and control exposure ( $30 \%$ of inclusion dose). sRaw: specific airway resistance; TGV: thoracic gas volume. 

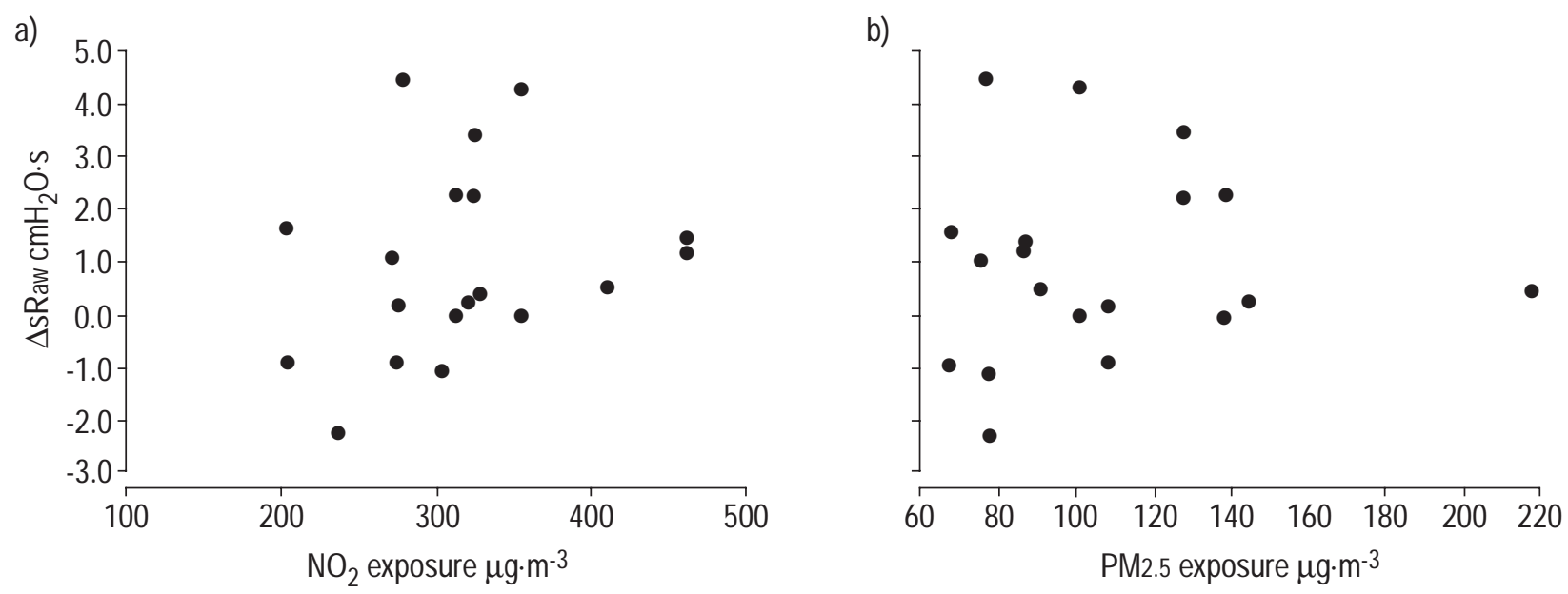

Fig. 1. - Asthmatic reaction during the early phase. Changes in specific airway resistance sRaw ( $\Delta$ s Raw) caused by allergen inhalation after tunnel exposure. Data are expressed as the difference from the values obtained on the control day. Negative values correspond to a greater effect on the control day compared to tunnel exposure. Individual differences between tunnel and control as a function of exposure to: a) nitrogen dioxide ( $\mathrm{rS}=0.36$, $\mathrm{p}=0.14$ ); and $\mathrm{b})$ particles with $50 \%$ cut-off $(\mathrm{PM} 2.5)(\mathrm{r}=0.14, \mathrm{p}=0.58)$ within the car.

used significantly more $\beta_{2}$-agonist inhalations compared to the group with exposure $<300 \mu \mathrm{g} \cdot \mathrm{m}^{-3}(\mathrm{p}=0.044)$. No such tendency could be seen for PM2.5.

In total, 18 subjects were followed with hourly FEV1 determinations during the late phase. On the day of the tunnel exposure, the maximal decrease in FEV1, at any time $3-10 \mathrm{~h}$ after allergen challenge, ranged $1.9-45.4 \%$ (median 8.8\%) compared to the (best) prechallenge FEV1, and the average late $\mathrm{FEV} 1$ values were from $2.2 \%$ higher to $23.5 \%$ lower (median $4.3 \%$ lower) compared to the prechallenge FEV1. On the control day, the maximal "decrease" in FEV1 ranged from 6.5 higher to $30.4 \%$ lower (median $7.0 \%$ lower) with the mean FEV1 being $6.5 \%$ higher $23.2 \%$ lower (median $2.6 \%$ lower) than the prechallenge FEV1. However, none of these changes differed significantly between the tunnel exposure day and the control day. However, among those with $\mathrm{NO}_{2}$ exposure $>300 \mu \mathrm{g} \cdot \mathrm{m}^{-3}$, the maximal decrease in FEV1 during the late phase was significantly greater $(\mathrm{p}=0.04)$ control (median $8.5 \%$ versus $6.8 \%$ ), and also tended to be greater ( $\mathrm{p}=$

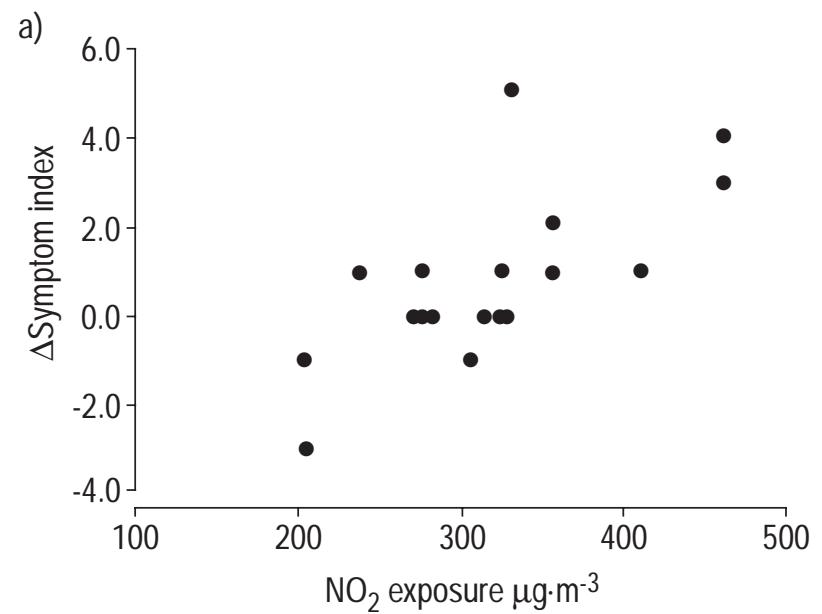

0.06) than that found in the group with exposure $<300$ $\mu \mathrm{g} \cdot \mathrm{m}^{-3} \mathrm{NO}_{2}$. Figure $3 \mathrm{a}$ presents the effect differences in the maximal late phase reaction between tunnel and control as a function of $\mathrm{NO}_{2}$ exposure within the car $(\mathrm{rS}=0.28, \mathrm{p}=0.26)$. There was a tendency for a greater late phase reaction in the group with PM2.5 exposure $>100$ $\mu \mathrm{g} \cdot \mathrm{m}^{-3}$ compared to control $(\mathrm{p}=0.051)$. There was no overall association between PM2.5 exposure and late phase change in FEV1 reaction (fig. 3b).

\section{Discussion}

The levels of $\mathrm{NO}_{2}$ and particulates measured in the road tunnel were higher than those observed in streets with heavy traffic in Stockholm, confirming earlier data [18]. The concentrations of $\mathrm{NO}_{2}$ inside the car were only slightly lower. The duration of exposure in a road tunnel depends on the length of the tunnel as well as the traffic situation, and is probably often shorter than in the present

b)

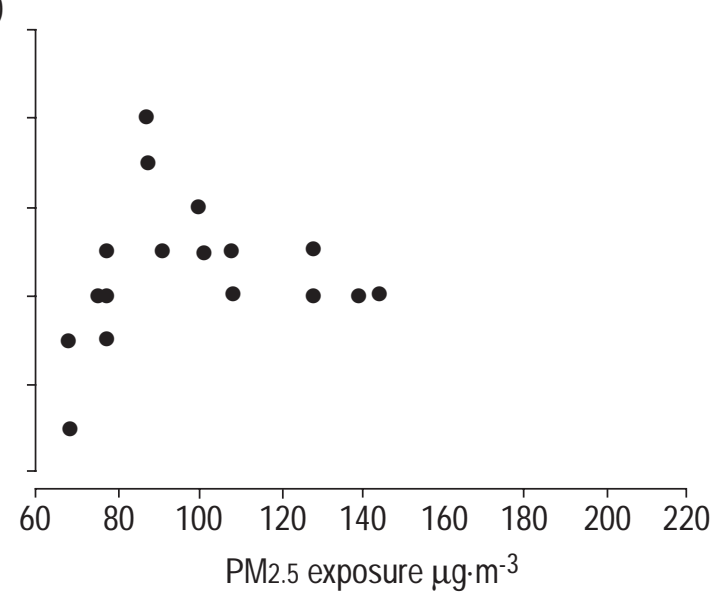

Fig. 2. - Asthma symptoms index during the late phase. Changes $(\Delta)$ in symptom index during the evening, night and morning after allergen inhalation. Data are expressed as difference from the values obtained on the control day. Negative values correspond to a greater effect on the control day compared to tunnel exposure. Individual differences between tunnel and control as a function of exposure to: a) nitrogen dioxide (rS=0.72; $\mathrm{p}=0.001$ ); and $\mathrm{b}$ ) particles with $50 \%$ cut-off aerodynamic diameter of $2.5 \mu \mathrm{m}$. (PM2.5) exposure $(\mathrm{rS}=0.32, \mathrm{p}=0.18)$ within the car. 

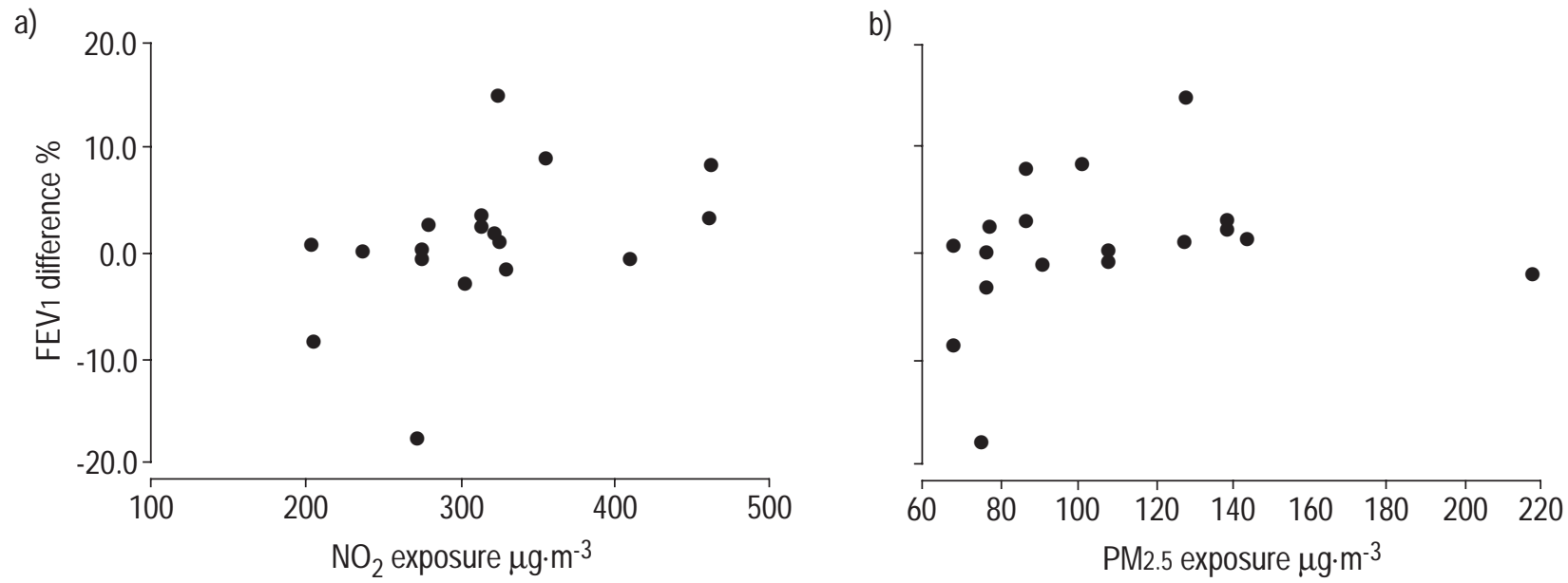

Fig. 3. - Asthmatic reaction during the late phase. Maximal late phase change in forced expiratory volume in one second (FEV1) (from best value). Data are expressed as the difference from the values obtained on the control day. Negative values correspond to a greater effect on the control day compared to tunnel exposure. Individual differences between tunnel and control as a function of exposure to: $\mathrm{a}$ ) nitrogen dioxide (rS=0.28, $\mathrm{p}=0.26$ ); and $\mathrm{b}$ ) particles with $50 \%$ cut-off aerodynamic diameter of $2.5 \mathrm{~mm}(\mathrm{PM} 2.5)(\mathrm{rS}=0.18, \mathrm{p}=0.46)$ within the car.

study. However, a 30-min exposure time is plausible in long tunnels or tunnel systems, and when traffic congestion occurs because of accidents or the rush hour. Moreover, this exposure time facilitates comparisons with earlier controlled chamber exposure studies [3, 4]. Data from the personal $\mathrm{NO}_{2}$ samplers indicate that the contribution from the tunnel exposure to total daily exposure is clearly discernible. Correlations between the concentrations of $\mathrm{NO}_{2}$ and particulates in the tunnel were weak, possibly due to the strong influence of the wet road surface on the particulate levels, leading to reduced resuspension of settled dust.

During the stay in the tunnel, the effects related to the airways, such as irritation with increased tendency to cough, breathing discomfort and chest tightness, were small or moderate. Pulmonary function, measured as FEV1 in the tunnel was similar to that in the morning, but there was an association between $\mathrm{NO}_{2}$ concentration and pulmonary function during the following morning hours. It must be taken into account that all subjects in the present study had bronchial asthma of a mild type with normal pulmonary function. People with asthma of a more brittle or severe type may have reacted differently.

For obvious reasons, it was not possible to blind the experimental design, and the subjects might have been more eager to report symptoms after the stay in the tunnel. However, not only was the magnitude of the symptoms greater during the tunnel day compared to control but also symptoms and the use of $\beta_{2}$-agonist inhalations were related to the exposure level of $\mathrm{NO}_{2}$ in the tunnel. The exposure concentrations were known to neither the subjects nor the personnel in the research group, when the experiment was performed. Furthermore, the consistency of the results is noteworthy concerning subjective symptoms, medication and changes in pulmonary function after allergen inhalation.

The health effect of main concern observed in the present study is the enhanced asthmatic reaction to allergen occurring several hours after the tunnel exposure. This finding is in agreement with earlier observations in controlled human exposure studies. In the study by STRAND et al. [3], a single exposure to $500 \mu \mathrm{g} \cdot \mathrm{m}^{-3} \mathrm{NO}_{2}$ followed by inhalation of a high dose of allergen resulted in an enhanced fall in PEF during the late asthmatic reaction and a tendency to increased early reaction to allergen. In a later study [4] of similar design with repeated exposure to $500 \mu \mathrm{g} \cdot \mathrm{m}^{-3} \mathrm{NO}_{2}$ followed by a low dose of allergen, there was an increase in both the early and late phase reactions. There was also a suggestion of increased symptoms of asthma during the night. In the current study, pulmonary function in persons with high $\mathrm{NO}_{2}$ exposure was affected during the early and late phase. They also had more asthma symptoms and used more medication during the late phase. The concentration of $\mathrm{NO}_{2}$ in the tunnel was, on average, considerably lower than that in the chamber studies, but an enhancing effect still appeared. This may be due to combined exposure to other air pollutants from car exhaust in the tunnel.

The associations between exposure and outcome variables were generally weaker for particulates than for $\mathrm{NO}_{2}$. A marginal effect of PM2.5 concentrations $>100$ $\mu \mathrm{g} \cdot \mathrm{m}^{-3}$ on the early asthmatic reaction as well as an association between PM2.5 concentration and asthma symptoms during the late phase was found in the present study. The latter was, however, highly dependent on one extreme data point. There might be important interactions between $\mathrm{PM} 2.5$ and $\mathrm{NO}_{2}$, but the limited number of subjects in the present study makes such an evaluation difficult.

To the authors' knowledge, there are no controlled human studies on the effects of particles on allergen responsiveness. Several epidemiological studies have also reported adverse health effects at rather low levels of PM10. For example, a US study showed an increase in hospital admissions at a PM10 level of as low as $24 \mu \mathrm{g} \cdot \mathrm{m}^{-3}$ [21]. Relatively low levels of particulate matter (PM10 $<60 \mu \mathrm{g} \cdot \mathrm{m}^{-3}$ ) may give rise to acute health effects and increasing need for medication in children [22]. It is not possible to evaluate whether interactions with allergens also played a role in these effects as relevant data were not reported. There is some evidence that exposure to the smaller fraction of particulate matter (PM2.5), may be more important than that to PM10 for acute respiratory symptoms [23] and even for death from respiratory diseases [24]. 
Unvented domestic gas appliances may contribute to $\mathrm{NO}_{2}$ exposure [25]. The seven subjects with gas stoves at home showed a higher $\mathrm{NO}_{2}$ exposure, measured using the personal sampler, on the tunnel exposure day. However, they did not differ in responsiveness to allergen (early and late phase and asthma symptom index) from the group without domestic exposure to $\mathrm{NO}_{2}$.

The allergens used in the present study were extracted from birch and timothy grass pollen, but it is likely that similar effects would be seen with other allergens (e.g. from cat, dog or mites) present all year round. TuNNICLIFFE et al. [2] showed that exposure to $800 \mu \mathrm{g} \cdot \mathrm{m}^{-3} \mathrm{NO}_{2}$ for $1 \mathrm{~h}$ amplified both the early and late reaction to mite allergen. The allergen dose used in the present study corresponds to natural exposure and can be obtained in a day during peak pollen season (ALK, Copenhagen, Denmark, personal communication). Similar effects on allergen responsiveness after $\mathrm{NO}_{2}$ exposure have been reported after lower, as well as higher, allergen doses [3, 4].

It is thus reasonable to assume that exposure to air pollutants for half an hour in a road tunnel can increase the bronchial response to allergens several hours after the exposure in individuals with allergic asthma. The findings suggest that exposure to car exhaust initiates a pro-inflammatory or inflammatory process in the bronchial mucosa. This state persists for $\geq 4 \mathrm{~h}$ and gives an extra impetus to the allergic reaction with accompanying deterioration of lung function. Such an interpretation, implying a pro-inflammatory effect of exposure to $\mathrm{NO}_{2}$ and particles, is supported by data obtained in human and animal exposure experiments [12]. If this interpretation is correct, it is also likely that the inflammation increases bronchial responsiveness to not only allergens but also nonspecific agents such as cold air and tobacco smoke, as well as exercise. The increase in bronchial responsiveness in the present study occurred without changes in lung function during exposure or in the interval before allergen exposure. There are other studies reporting similar findings with no observed effect on lung function during $\mathrm{NO}_{2}$ exposure, but which induced an increase in airway responsiveness to agents like histamine, methacholine or ozone [2, 26, 27]. This makes it difficult for the exposed individual to be aware of the risk.

In conclusion, short-term exposure to air pollution in a road tunnel during the rush hour enhanced the asthmatic response to allergen inhaled several hours later, although pulmonary function during the exposure was not affected. The adverse effect was related to the exposure levels of nitrogen dioxide and, to some extent, to particles, and merits attention from a public health perspective as large groups of the population with asthma may be at risk.

Acknowledgements. The authors would like to thank P-A Johansson, K-G Westerlund, Stockholm Air Quality and Noise Analysis for carrying out exposure-related measurements, A-S Lantz, K. Ornefalk and L.G. Persson for taking care of study subjects, symptom registration, and pulmonary function measurements, and $\mathrm{K}$. Örnefalk also for measurement of personal exposure to nitrogen dioxide.

\section{References}

1. Folinsbee L, Beem LJ. Does nitrogen dioxide exposure increase airway responsiveness? Toxicol Ind Health 1992; 8: 273-283.

2. Tunnicliffe W, Burge P, Ayres J. Effect of domestic concentrations of nitrogen dioxide on airway responses to inhaled allergen in asthmatic patients. Lancet 1994; 344: 1733-1736.

3. Strand V, Rak S, Svartengren M, Bylin G. Nitrogen dioxide exposure enhances asthmatic reaction to inhaled allergen in subjects with asthma. Am J Respir Crit Care Med 1997; 155: 881-887.

4. Strand V, Svartengren M, Rak S, Barck C, Bylin G. Repeated exposure to an ambient level of $\mathrm{NO}_{2}$ enhances asthmatic response to a nonsymptomatic allergen dose. Eur Respir J 1998; 12: 6-12.

5. Utell MJ, Morrow PE, Hyde RW. Comparison of normal asthmatic subjects responses to sulphate pollutant aerosols. In: Walton VH, ed. Inhaled Particles V. Proceedings of an International Symposium, organized by the British Occupational Hygiene Society; September 1980; Cardiff, Wales. Ann Occup Hyg 1982; 26: 691-697.

6. Dockery DW, Pope CA 3rd. Acute respiratory effects of particulate air pollution. Ann Rev Public Health 1994; 15 : $107-132$.

7. Schwartz J. Short term fluctuations in air pollution and hospital admissions of the elderly for respiratory disease. Thorax, 1995; 50: 531-538.

8. Lipsett M, Hurley S, Ostro B. Air pollution and emergency room visits for asthma in Santa Clara County, California. Environ Health Perspect 1997; 105: 216-222.

9. Delfino RJ, Murphy-Moulton AM, Burnett RT, Brook JR, Becklake MR. Effects of air pollution on emergency room visits for respiratory illnesses in Montreal, Quebec. Am J Respir Crit Care Med 1997; 155: 568-576.

10. Atkinson RW, Anderson HR, Strachan DP, Bland JM, Bremner SA, Ponce de Leon A. Short-term associations between outdoor air pollution and visits to accident and emergency departments in London for respiratory complaints. Eur Respir J 1999; 13. 257-265.

11. Castellsague J, Sunyer J, Saez M, Anto JM. Short-term association between air pollution and emergency room visits for asthma in Barcelona. Thorax 1995; 50: 10511056.

12. American Thoracic Society. Health effects of outdoor air pollution. Am J Respir Crit Care Med 1996; 153: 3-50 and $477-498$.

13. Rudell B, Ledin MC, Hammarstrom U, Stjernberg N, Lundback B, Sandstrom T. Effects on symptoms and lung function in humans experimentally exposed to diesel exhaust. Occup Environ Med 1996; 53: 658-662.

14. Blomberg A, Sainsbury C, Rudell B, et al. Nasal cavity lining fluid ascorbic acid concentration increases in healthy human volunteers following short term exposure to diesel exhaust. Free Radical Research 1998; 28: 59-67.

15. Weeke B, Poulsen LK. Diagnostic Tests for Allergy. In: Holgate ST, Church MK, eds. Allergy. London, Gower Medical Publishing, 1993; pp. 11.1-11.14.

16. Berglund M, Vahter M, Bylin G. Measurement of personal exposure to $\mathrm{NO}_{2}$ in Sweden - evaluation of a passive sampler. $J$ Exp Anal Environ Epidemiol 1992; 2: 295-307.

17. Du Bois AB, Bothelo SY, Bedell GN, Marshall R, Comroe JHJ. A rapid Plethysmographic method for measuring thoracic gas volume; comparison with a nitrogen washout method for measuring functional residual 
capacity in normal subjects. J Clin Invest $1956 ; 35$ : $322-$ 326.

18. Du Bois AB, Bothelo SY, Comroe JHJ. A new method for measuring airway resistance in man using body plethysmograph; values in normal subjects and in patients with respiratory disease. J Clin Invest 1956; 35: p. 327.

19. Nieminen MM, Lahdensuo A, Kellomaeki L, Karvonen J, Muittari A. Metacholine bronchial challenge using a dosimeter with controlled tidal breathing. Thorax 1988; 43: 896-900.

20. Basu M, Bluhm G, Gustavsson P, et al. Health risk assessment of air pollution in and around road tunnels in the county of Stockholm. Rapport 30/95. Department of Environmental Health. Stockholm County Council. (in Swedish) 1995.

21. Schwartz J, Slater D, Larson TV, Pierson WE, Koenig JQ. Particulate air pollution and hospital emergency room visits for asthma in Seattle. Am Rev Respir Dis 1993; 147: 826-831.

22. Gielen MH, van der Zee SC, van Wijnen JG, van Steen
CJ, Brunekreef B. Acute effects of summer air pollution on respiratory health of asthmatic children. Am J Respir Crit Care Med 1997; 155: 2105-2108.

23. Romieu I, Meneses F, Ruiz S, et al. Effects of air pollution on the respiratory health of asthmatic children living in Mexico City. Am J Respir Crit Care Med 1996; 154: 300307.

24. Schwartz J, Dockery DW, News LM. Is daily mortality associated specifically with fine particles? J Air Waste Manage Assoc 1996; 46: 927-939.

25. Spengler JD, Sexton K. Indoor air pollution:a public health perspective. Science 1983; 221: 9-17.

26. Hazucha MJ, Folinsbee LJ, Seal E, Bromberg PA. Lung function response of healthy women after sequential exposures to $\mathrm{NO}_{2}$ and O3. Am J Respir Crit Care Med 1994; 150: 642-647.

27. Strand V, Salomonsson P, Lundahl J, Bylin G. Immediate and delayed effects of nitrogen dioxide exposure at ambient levels on bronchial responsiveness to histamine in subjects with asthma. Eur Respir J 1996; 9: 733-740. 